\title{
Dutch Healthcare Professionals Experiences of Assisted Dying: A Constructivist Qualitative Study Conducted in a Chronic Disease Care Centre and Hospice.
}

Deborah Lewis ( $\nabla$ deborahann.lewis@btinternet.com )

Lancaster University https://orcid.org/0000-0002-5586-5170

Nancy Preston

Lancaster University

Research article

Keywords: Assisted Suicide, Qualitative Research, Health Personnel, Hospices, Hospice Care, Palliative Care, Emotions

Posted Date: August 2nd, 2019

DOI: https://doi.org/10.21203/rs.2.11826/v1

License: (1) This work is licensed under a Creative Commons Attribution 4.0 International License.

Read Full License 


\section{Abstract}

Background: Assisted dying is a contemporary issue, but comprehensive consideration of healthcare professionals' experiences has been lacking. This study sought to gain a deeper understanding of professionals' experiences of assisted dying to inform the global debate surrounding its implementation. Methods: This constructivist, qualitative study, recruited twenty-one physicians, nurses and therapists from a Dutch chronic disease care centre and a hospice. Data were gathered in semi-structured interviews, conducted in English. Questioning focused on professionals' experiences along a clinical trajectory from an initial request to beyond the death. Data were subjected to thematic analysis to identify main and subthemes. Results: Analytical procedures generated four broad themes 'Assessment and its Challenges', 'Preparing Staff and Learners', 'Assisting a Death' and 'Bereavement Care and Beyond', supported by subthemes. Assessment of requests involved all professional groups and required open dialogue, exploration of fears, palliative care optimisation and psychological evaluation. Such measures resolved the majority of requests. Assisted deaths were challenging, required careful management and were not perceived as normal. Administration of lethal drugs and reporting procedures were stressful for physicians. Structured debriefing and proactive psychological support were valued by all professionals, but resolving their emotions took time. Some physicians required a recovery period creating equity of access issues. Life and care experience aided the preparation of professionals, but resilience was also needed. Support for the provision of assisted dying was overwhelming, but this was unqualified in only a third of participants. Conclusions: Assisted dying creates significant challenges for healthcare professionals who require preparation and support. This is likely to require enhanced levels of palliative care education, legislative advice, and proactive psychological support to ensure professionals' own wellbeing. Meeting these needs will have financial implications which should be addressed prior to implementing legislation which permits assisted dying.

\section{Background}

Assisted dying is a contemporary, but controversial and sensitive topic defined as:

\section{"... assisted suicide and voluntary euthanasia when a person receives assistance from a third party to end their life." (1)}

Currently, it is permitted in a limited number of jurisdictions, a 'jurisdiction' being defined as a country, state or federal district. Global variations exist in exist in the terminology used and the practices permitted (Table 1). This article will use terms as defined in the Netherlands where the study was conducted. Euthanasia relates to a medically administered death and physician-assisted suicide describes selfdelivery by the patient. However, in the Netherlands both forms of death require a physician's presence at the time of death (2).

The ethical and legal aspects of assisted dying are intensively debated, but pragmatic issues related to its implementation have received less attention (3). Prognostication uncertainty, assessing psychological 
status, loss of emotional growth for the patient, desensitization of professionals and opioid increase being seen as synonymous with assisting dying have all been identified as concerns (3). In addition, where it is permitted, professional's need to consider their personal stance and ability to best support patients, but little is known about such work. This study, conducted in the Netherlands, sought answers to the pragmatic realities of permissive legislation from professionals prospective. This is highly topical as the number of jurisdictions permitting assisted deaths is small, but increasing.

\section{Assisted Dying Legislation in the Netherlands}

The Termination of Life on Request and Assisted Suicide Act of 2002, or Euthanasia Act (4), formalised the already established practices of euthanasia and physician-assisted suicide in the Netherlands. Prior to 2002 the term 'euthanasia' was synonymous with several end-of-life care practices, but a lack of clarity resulted in contentious cases being brought before Dutch courts. With a high degree of public interest, such cases led to formal legislation, the development of which is comprehensively documented (5).

The Dutch law requires a voluntary, non-coerced request for an assisted death from the patient. Six due care criteria have to be met. These include suffering which is "unbearable" (4), which can relate to physical or psychiatric illness, but requests also need to be voluntary, informed, consistent and enduring. Assessment by an independent physician, often sought from the Royal Dutch Medical Association support services (6), is compulsory. If a lack of capacity, or depression, is suspected a psychiatric consult is also mandatory. Physicians are provided with the Euthanasia Code (7), which includes guidance on advanced directives, patients with reduced consciousness, psychiatric disorders, dementia or intellectual disability. Assisted deaths constituted $4.6 \%$ of all deaths in the Netherlands in 2017 with medical administration being the most common practice (95.8\%) (8). Patients can also self-ingest lethal drugs, but a physician still needs to be present. All professionals have a right to object and can decline involvement (9).

\section{Reporting and Scrutiny Procedures}

Contrasting with other jurisdictions $(10,11)$ a Dutch assisted death is not classified as 'natural' $(12)$. Consequently the patient's hospital or family physician is unable to complete a death certificate. Instead the Public Prosecutor's Office is informed with a local pathologist (12) viewing the body and paperwork before filing a report. If due care criteria appear to have been followed permission for cremation or burial will be given and the Regional Euthanasia Review Committee (12) notified.

Review Committees are allowed six weeks to report conclusions to physicians with a further six weeks permitted for additional investigations (4). Cases can be assessed digitally initially, but $25 \%$ of notifications raise additional questions reviewed within monthly meetings. The Public Prosecution Service and Medical Inspectorate, who can sanction individuals and organisations, can either endorse 
Committee decisions, or make additional recommendations (12). No physicians had been prosecuted until recently, when a case of improper conduct following the death of an elderly dementia patent in 2017 (13), was referred for court review.

\section{Other Developments}

Founded in 2012 by the Dutch Association for Voluntary Euthanasia, the End of Life Clinic [Levenseindekliniek] (14) is subjected to same scrutiny outlined above, but has been seen as a controversial development (15). The clinic assesses patients who desire death, but whose regular physician does not participate or has rejected their request (16). Patients are assessed by a physician and nurse team in their place of residence. If the request is considered potentially valid a consulting physician and lawyer will make additional assessments. Approximately fifty percent of all requests received by the End of Life clinic are refused (16). Demographically, patients are older than the general population with a higher probability of dementia or psychiatric illness (16).

\section{This study}

This study focused on a sample of Dutch physicians, nurses, and therapists to access the experiences of permitting assisted dying for professionals and their organisations. Ethical approval for the study was granted by the Lancaster University's Faculty of Health and Medicine [FHMREC12017]. Non-invasive research recruiting staff in the Netherlands does not require full ethical approval (17), but a proposal was submitted to the Maastricht University Executive Committee [METC12-5-043] and held on file.

Philosophical Approach of the Study

Ontologically, this study took a relativist constructivist approach which acknowledges that multiple realities exist in the social world (18). Accounts gathered from the participants are constitutive in nature and are, in turn, interpreted by the researcher. Therefore, rather than aiming for an absolute truth, truth can

be defined as the best informed construction of a phenomenon with consensus based on the quality, and power of the supplied information (19). Constructivism requires research methods that are responsive and iterative (19). Therefore, qualitative methodology was utilised to explore the reality of assisted dying from the perspective of professionals. Qualitative methods generate large amounts of data and several thematic analysis conventions exist. Here, a phased approach by Braun and Clarke's (2006) was applied to manage, describe, and interpret the data. Its six phases are discussed in more detail later.

\section{Reflexivity}

Researcher reflexivity is required in qualitative research acknowledging personal background, potential power imbalances and the influence of social context on the accounts given (18). Assisted dying research 
should also acknowledge the enquirer's personal values and their perspectives informing the study. The Principal Investigator [DL] is a Registered Specialist Nurse/Lecturer in Palliative Care. Data collection and analysis therefore, was aided by knowledge of healthcare professionals' roles, and of end of life care. However, care was taken to express no moral stance on assisted dying to encourage frank and open disclosure of participants' experiences.

\section{Methods}

\section{Research Sites}

Access to research sites aboard is often conducted through professional networks (20) and through contacts it was possible to negotiate access to a chronic disease care centre (Site A) and a hospice (Site B). Site A was the larger organisation employing 91 staff whilst Site B, the hospice, employed 41 staff. Permission to recruit staff was granted by the Boards of the two organisations.

\section{Sampling and Recruitment}

Qualitative studies do not seek statistical significance and, consequently, optimal sample sizes are not definable (21). Non-probability purposive sampling recruited a variety of practitioners with assisted dying experiences to inform the research from multiple angles of vision (22). An invitation to participate, which included the aim of the study, was send to all staff via internal email. A Participant Information Sheet and Consent Form were supplied to professionals who expressed an interest in participating. In total twentyone physicians, nurse and therapists were recruited (Table 2).

\section{Data Collection and Analysis}

Interviews were conducted by DL in a quiet room situated away from the clinical area. Prior to commencing the interview the purpose of the study was reinforced and Consent Forms read through, signed and dated. Audio-recorded, semi-structured interviews in English, supported by field-notes, followed a flexible questioning guide (Table 3 ) with alternative questions for professionals who conscientiously objected to assisted dying. Although the standard of English spoken by the participants was high translating thoughts can be tiring. As a consequence the average interview length was 23 minutes.

Interviews were transcribed, checked against the original recordings and coded by DL using Microsoft Word. After the identification of a list of initial codes, thematic analysis followed Braun and Clarke's (23) phased schema to identify main and subthemes, across the data set.

\section{Validity, Reliability and Rigor}

Constructed truths are dynamic, varying across time and place, but qualitative research needs to demonstrate rigor to be credible. Systematic analytical procedures, using quotes to demonstrate data strength (24), including negative cases and multiple field visits by DL (25), strengthen this study's 
credibility. Member-checking (26), a presentation of the provisional results to participants in an Open Invitation Research Summary, was also used. No offer to withdraw material was made, but additional insights were included in the results.

\section{Results}

Data amalgamation and analysis generated four broad themes and subthemes. Broadly these follow a clinical trajectory from an initial request to beyond bereavement care (Table 4). Novel themes, and those answering pragmatic questions about assisted dying implementation (3), are included here.

\section{Main Theme: Assessment and Its Challenges}

\section{Frequency of Requests, Exploration and Negotiation, Personal Characteristics}

Regardless of professional role, all participants had experienced expressions of interest, or talked to patients, about assisted deaths. Patient's vocalisations were usually exploratory, but assessing seriousness was needed. No resentment was expressed, but this impacted on workloads particularly at the hospice (Site B) where "fifty percent" (P4) of admissions sought such dialogue. Open dialogue, endof-life care experience and legal knowledge were considered essential as patients often lacked such knowledge. Some patients considered assisted dying "too easily" (P17) and seeking clarity of reasoning, the "question behind the question" (P4), was essential. Common fears expressed by patients related to care quality, poor symptom control and the dying process according to the participants.

Requests were often retracted after exploration and resolution of patients' fears, but at the larger research site (Site $A$ ) enduring requests were reviewed in multidisciplinary meetings. If a team consensus could not be reached a request was more likely to be refused (P11). At the hospice (Site B) such meetings did not take place. As a consequence some nurses (P3) attended deaths about which they felt uncomfortable, having not being involved in the decision-making. The tenacity of patients was also highlighted with some going to extraordinary lengths to gain an assisted death, including transferring from non-permitting to permitting institutions and enduring assessments which lasted months. Participants felt educated and articulate patients were more likely to have requests granted (P8). Other personal characteristics such as the fear of burdening others and valuing autonomy were also highlighted. Modern lifestyles were also cited as a contributing factor:

"They have birth control and financial control and now they want death control." (P2) 
Requests made too late in the disease trajectory, and if family coercion was suspected, were refused. Notably, in chronic disease, some participants felt patients were grateful (P5, P11) for a request refusal. According to participants sometimes refused patients moved on to new and rewarding roles such as becoming a Grandparent (P5).

\section{Support and Conscientious Objection}

The majority of participants initially expressed support for assisted dying, but during interviews a more complex picture emerged. Several applied qualifications to their support. These included physicians exercising objection to specific patient groups such as those with dementia. Some professionals highlighted this inequality of access for dementia patients as unfair, but for some physicians it was a "step too far" (P11) and they declined involvement. Some participants approved of the patients' right to discuss assisted dying, but doubted it was ever a good option (P17, P18). Assisted deaths were also more acceptable in somatic disease, particularly if symptoms were intractable, than in psychiatric illness (P9). Moreover, good medical care, careful assessment of requests and care in life termination, was a prerequisite for participation of some nurses (P7, P20). Without these elements they felt able to withdraw their support. Being vigilant of the potential for abuse was also reported.

Only one participant, working at the hospice, had a moral objection to assisted dying (P2). However, despite her stance she was required to assess requests before passing them on to a participating colleague. Seen as onerous, this challenged her emotionally:

"I can totally understand this patient wants euthanasia, but that does not mean that I want to do it" (P2).

Cited as a cause of frustration and stress, particularly when relatives did not understand she could not simply "kill the patient" (P2) it was also suggested assisted dying led to difficulties in retaining some hospice medical staff.

\section{Palliative Care, Changing Minds and Boundaries}

Unbearable suffering, a key legal criterion, is recognised as problematical to assess (27). To overcome this problem physicians' focused on optimising palliative care to decide if suffering was remedial. An experienced physician (P11) explained:

"The first challenge is to optimise my palliative care for these patients...you ask yourself 'did I do everything I could to make this suffering bearable." 
Professionals valued palliative care highly. Several had undertaken extra training and cited an increase of palliative care use over the time. However, the increase in the number of Dutch palliative care providers has followed, rather than preceded, assisted dying legislation (28). This frustrated some professionals especially those with a moral objection, but others (P9, P18) were more circumspect highlighting that even their best efforts did not always resolve suffering. Notability however, simple strategies to overcome disability, such as providing a wheelchair and more complex procedures, such as artificial feeding, delayed some assisted deaths particularly in patients with chronic disease. Referral to a pain specialist resulting in a nerve block was also cited as eradicating a request (P5).

\section{Psychological Status}

Assessing psychological status at life's end is problematical (29). If mental health issues are suspected, a psychiatric opinion is mandatory, but at the chronic disease care centre (Site A) patient review by a psychologist was standard practice. Unfortunately, this professional was not recruited so detailed knowledge of their role is lacking. Nurses however, highlighted their ongoing observation of patients' mood, facilitated by the continuity of their care. Patients had 'good and bad days'(P14) influencing the consistency of their requests and, if some rehabilitation was possible, they became more positive.

\section{Assessing and Supporting Families}

Families were assessed by a social worker if one was available (Site A). Comprehensive knowledge of the role undertaken by social workers in assisted dying has been reported as lacking (30). However, in this study, the social worker was clear about the scope and boundaries of her role. After meeting the patient, she assessed the family's ability to support, and cope with, the patient's choice of death. Often, family members needed help to deal with conflicted emotions:

"They may have the feeling they are not important enough to stay alive for. They have to deal with it and it is difficult. They say, 'He needs help and I can't give him the help. I have failed'. Or 'I don't want to be selfish' [wishing life]. Those feelings come and go'." (P9)

Attempts were also made to prepare children if old enough to understand a planned death. However, in the absence of a social worker (Site B), nurses took on some elements of this role, although some families prepared children themselves.

Other professionals developed close relationships with patients and their families. Although sometimes emotionally demanding, these were viewed as valuable learning experiences. A young nurse (P10) described a young couple's reaction to the husband's assisted death:

"It was beautiful to see how man and wife communicate with each other and it was unbelievable." 
Prior to the death the nurse organised activities including nice meals for the couple on the ward.

\section{End of Life Clinics: Challenging Safe Assessment?}

Only one participant (P4) had direct experience of the death of a nursing home resident performed by the End of Life Clinic (14), but several cited concerns. These related to the clinic's staff's lack of a long-term relationship with the patient and family as a physician (P11) explained:

"....euthanasia is something that is part of a treatment trajectory you go through together as a patient and the physician. It feels wrong if patients can go to a clinic getting their euthanasia as a sort of product, should not be like that."

Participants suggested the clinic challenged legal boundaries, but none suggested it was acting unlawfully. Others highlighted the challenges of adequately assessing requests in busy hospital environments, such as outpatients, where ten minute consultations are the norm. A physician (P18) explained:

"...they say [the clinic] 'we have at least four conversations one hour'. They say they know the patient better than the patient's General Physician [GP]. If they work very carefully, take their time, they can come to a right decision, a reasonable judgement."

Other participants suggested the clinic had a useful role in supporting inexperienced physicians in administering lethal drugs, an issue highlighted later.

Main Theme: Preparing Professionals

Eighteen years of Dutch assisted dying legislation was cited by some participants (P4) as adequately preparing professionals for their role, but not all agreed. Averij [pronounced A-ver-lay], meaning to 'sustain heavy damage', was also used by one nurse (P5) to describe the resilience professionals needed to care for such patients. Such resilience, it was suggested, arose from life and care experiences (P5):

"You can prepare for it, but the most of what you have to have is life experience 'averij'. I have seen in life what illness can do to people. You can be sick for long years and, now and then, when someone says 'No, it is enough'. It is enough."

Understanding the legal boundaries of their role by accessing online learning and case study review was seen as helpful preparation, but assisted deaths were emotionally demanding particularly for less experienced professionals. The need to prepare clinical students on placements was also identified with concerns they need, but may not have access to, the same level of support as qualified staff. 


\section{Main theme: Assisting a Death}

\section{Final Requests, Managing the Death}

The date and time of the death were negotiated with the patient and family. Allowing patients to attend to personal matters they often made final requests, some simple, others more elaborate. Simple requests included a final cigarette or favourite meal. The more elaborate included making keepsakes for families, filming videos, organising afternoon tea for friends, and aromatherapy, make up and favourite lingerie donned prior to death. Participation of professionals in such activities was viewed as rewarding and 'special' work (P9, P10, P13). Some professionals also gained an enhanced appreciation of the impact of illness on the patient (P5).

Careful management of the death, to protect staff, was needed. Additional personnel, sometimes experienced volunteers, were rostered to provide extra support. Nurses caring for the patient were allowed to go home after the death. Nurses aimed for "peace around the bed" (P6), but such deaths were hard to hide from other patients. Mindful of confidentiality professionals had to be prepared for questions. Deaths, in cases of family conflict, could result in harrowing scenes and careful negotiation of those present was recommended (P6, P17).

\section{Administering Lethal Drugs}

Specific Dutch drug protocols exist (31). Self-administration of lethal drugs is permitted, but because of well-published concerns about drug efficacy of oral or feeding tube administration (32), physicians overwhelmingly favoured intravenous delivery. Dutch physicians' presence is required even if selfadministered, but for some physicians it was an ethical as well as a legal, issue. Viewing the Death with Dignity Acts in the United States as "saying 'OK that's it, see to it yourself" (P11), providing patient support at death was seen as a medical responsibility.

Several physicians however, identified emotional challenges in administering lethal drugs. Some, after cannulation, requested help from a more experienced colleague. Relative youth, a lack of experience and a long-standing patient-physician relationship were cited as reasons for this problem. A seemingly confident physician (P18) explained:

"I'm thirty-two for the record. I can discuss with the patient, with the team and agree it is the best option, but to take away the life in a moment and inject the medication that is something else. I believe I'm not still ready for that."

Swiftness of death after intravenous delivery surprised many participants occurring in 'seconds' or occasionally 'minutes'. Moreover, a physician (P2) with an objection to such deaths suggested that repeated exposure may not lessen impacts:

"I had a colleague who was all for it [assisted dying] and she's 'I can't do it anymore' because even if you are in favour of it, it becomes a burden when you do it three or four times. It is stressful to kill somebody." 
Other professionals with experience of more than one assisted death did not suggest it became easier.

\section{Its' Never Normal}

Assisted deaths were not viewed as normal with an impact differing from a natural death. After death procedures for physicians, reported later, may intensify such feelings. However, other practitioners also identified a 'strange atmosphere' when a planned death was due to take place. A hospice nurse (P20) reported:

"It is always a little bit strange that someone is going to die tomorrow at seven o'clock. It is very strange."

Several staff discussed the value of discussing such deaths openly not only with each other, but also in a wider context with continued societal debate considered a 'good thing'. Most participants, although broadly in favour, reported a heightened sense of loss when a patient died with assistance.

\section{Main Theme: Bereavement Care and Beyond}

\section{Waiting for the All Clear}

Unable to supply a death certificate, completing multiple forms and contacting the local Prosecutor's Office was onerous for some physicians (P11, P21). Waiting for Review Committee judgements also led to a period of uncertainty. Since conducting the interviews a lighter touch approach by Review Committees to less contentious cases has reduced waiting times, but in complex cases it can run into months. One physician (P21) questioned the legality of Dutch assisted deaths (P21) with all subjected to a form of judicial review:

"... it doesn't feel OK when you do something to help a patient and then you are [potentially] prosecuted for murder until they say you won't be prosecuted. It is a very strange feeling. It's OK they are very strict about it, but if the protocol is followed you have to make it legal or illegal, but not this strange loop they now use."

Less experienced physicians suggested the reporting procedures afforded legal protection, but as noted earlier physicians can be prosecuted for wrong-doing.

\section{Emotional Responses and Coping Strategies}

Responses immediately after the death ranged from a sense of disbelief (P14), to "relief" for the patient (P3), or feeling "very heavy" (P14), a word often used by participants to describe sadness. Some felt personal satisfaction in helping the patient achieve their aim, but for others, cases had a longer-term effect. Notably, for some physicians (P11) this influenced their ability to consider new requests raising access issues:

“...it has a lot of impact. For me it takes a year before I get over it and think 'Ok, now I'm ready for a new trajectory."(P11). 
Remembered for years in some cases, memories were triggered by unexpected events, although recollections were not always a 'burden' as a physician (P13) explained:

"Still now, when I enter his room I still think of it. You will always remember it, but it's not burdensome".

Coping strategies cited included case discussion with colleagues, talking to partners and the distraction of conferences. More formally, a psychologist was proactive (Site A) visiting the ward to talk to staff. Debriefing meetings were also held and, despite being emotional, these were highly valued and considered invaluable for less experienced colleagues. Formal debriefing was not mentioned at the hospice (Site B), but "talking, talking, talking" (P3) was a popular strategy amongst the nurses to aid closure. Visiting physicians at the hospice had tea with the ward manager which she viewed as an importance supportive measure.

\section{Discussion}

Assisted dying continues to be a controversial, ethically sensitive issue, but it is becoming an option for patients in an increasing number of jurisdictions. However, it is challenging work and for professionals, and organisations considering their willingness to participate, this study highlights many issues worthy of consideration. It answers some of the pragmatic questions that have been posed by others (3), but also highlights more theoretical aspects of assisted dying which may warrant further research.

\section{An 'Abnormal' Death}

Despite being legally permitted since 2002 assisted deaths were viewed as 'never normal'. Such feelings, expressed across all professional groups, differed from an objection to its practice, as the majority of participants were broadly in favour. Moreover, such feelings existed beyond the first experience. Only tentative conclusions can be reached, but it is possible that professionals may not, in facilities where high standards prevail, become desensitised to such deaths, a commonly voiced concern (3). Instead greater emphasis on preparing and supporting professionals for the challenges assisted dying brings may be warranted.

\section{Preparing for Requests}

Physician and nurse involvement in requests is predictable. This study however, suggests patients are indiscriminate to whom they direct requests, seeking dialogue with therapists from many disciplines. Therapists' involvement widens considerably the number of professionals who require preparation for such work. More therapists may also be needed in professions such as social work and psychology. This may have significant financial implications, a factor rarely considered in assisted dying debates. Suggestion have been made that implementing permissive legislation can be cost neutral (33), but responding to requests requires sensitivity, exquisite communication skills, and end of life care knowledge. Experience was helpful, but training and education packages for staff, perhaps for a variety 
of levels of participation need to be considered. Many requests will be resolved by other means such as resolving fears or palliating symptoms (34), but, this study suggests, professionals may have a significant influence on the outcome. To ensure patients are safeguarded, professionals need to be adequately counselled and prepared for their role.

Fluidity in support for assisted dying was evident, but receiving requests had a significant impact on practitioners with a moral objection. Organisations who decide to participate need to consider the support requirements of professionals who abstain. If lacking, objectors may leave the organisation. This potentially increases the risk of institutional bias towards granting assisted dying requests. Maintaining a diversity of opinions may help to foster a climate which safeguards patients as some, it should be recognised, may later be grateful for a refused request. Pragmatically, in organisations where nonparticipating professionals are likely to receive requests, negotiation of their involvement level on an individual basis may be one method of ensuring consideration of their needs. The demands of such work may however, lead to professionals and organisation declining involvement. Research, such as this study, may help to inform such choices.

\section{Palliative Care}

Palliative care's role is contested and controversial (35). By definition, it is an approach which focuses on an intention to neither hasten nor postpone death (36). Pragmatically however, its use was viewed as paramount for those seeking an assisted death by professionals who integrated it into care.

Fundamentals such as open dialogue, symptom resolution and integration of psychological and social dimensions were evident. Such findings may be helpful in exploring the relationship between palliative and assisted dying where the two coexist. Of vital importance is the suggestion that interventions, such as nerve blocks and artificial nutrition, may alter patients' choices. Other Dutch studies (37) highlight intensified palliative care prior to assisted deaths, but more recognition is needed that instigating simple measures such as feeding assistance or wheelchair access may delay requests. This may be particularly pertinent for chronic disease patients in jurisdictions where they may be eligible for an assisted death. Such measures may extend the life of some patients even if, ultimately, they choose an assisted death.

\section{Short and Longer Term Impacts}

Administering Lethal Drugs (Physicians)

The impact of administering lethal drugs for the first time has been reported (38), but this study adds detail. The impact of terminating life, particularly for younger and less experienced physicians is lacking 
in official guidance $(9,31)$. Arguably, Dutch physicians have good support via their professional association (6). However, beyond the Netherlands such issues are not confined to physicians. Recent Canadian legislation (39) extends lethal drug delivery to nurse practitioners. This study suggests they may need to be supported and prepared for an emotional impact, which may not diminish over time. Hypothetically, it is suggested that self-delivery by the patient (physician-assisted suicide) may lessen the impact on professionals (40). Whether or not this is the case appears to be unknown and more research in this area is warranted. Historically, self-administration has been more commonly used at the Dutch End of Life Clinic (41) than in the wider population, but the reasons for this appear to be unreported.

\section{Equity and Equality of Access}

Assisted dying cases were exacting and placed significant demands on professionals. Ultimately, this impacted on physicians' abilities to consider requests from other patients raising equity and equality issues, a topic often lacking consideration (42). Professional guidance (9) suggests Dutch physicians can refer cases to a colleague. Practically however, gaining an alternative medical opinion may be difficult. Hypothetically, this may drive Dutch patients to other care providers such as the End of Life Clinic (14) whose case numbers have increased steadily since its inception (8). In this study there was no suggestion by staff that this clinic operated outside of the law and, in its first year, the clinic rejected $46.5 \%$ of all requests (16), but several participants expressed concerns. Specifically, their concerns related to the clinic's lack of long-standing knowledge of the patient and of their social background, such as might be known by a family doctor. This lack of care continuity, it was suggested, might compromise patient safety. There were also concerns that the clinic's staff might not be adequately competent for the complexities of the work. Assessments of these issues were beyond the remit of this study, but issues related to the equity and equality of access to an assisted death were raised.

\section{Emotional Impact and Potentially Supportive Strategies}

Psychological impacts related to natural deaths are reported $(43,44,45)$, but studies focused on the impact of assisted deaths on professionals are lacking. Impacts of natural deaths may be heightened by close relationships $(43,44)$ and, in this study, participants developed close bonds with assisted dying patients and their families. These developed over the weeks, or sometimes months, of assessment. After the death, contact with the families was valued, but some professionals also made long-term commitments suggesting that assisted deaths may have a heightened impact.

Practically, some professionals found post-death debriefing sessions helpful and there is evidence, related to natural deaths, that such discussions can support staff (44). Structured debriefing has also been shown to aid the development of nurses' clinical reasoning skills (46). Exploring its potential in reducing the impact of assisted deaths may be informative. In this study professionals also found talking to colleagues, psychological support from a line manager, the availability of a psychologist, and employee support programmes, as valuable. Ensuring access to such services prior to implementing assisted dying may be desirable. Other studies suggest nursing students (47), and less experienced 
nurses, find deaths more impactful (44). Organisations and educational providers therefore, need to ensure supportive strategies include the newly qualified and students on clinical placements.

\section{Limitations of the Study}

Assisted dying is a controversial topic. This may have impacted on the information professionals wanted to divulge. Also, as a qualitative study, only a snapshot of professionals' experiences and experiences can be constructed. Qualitative enquiry accepts that complete researcher neutrality is also impossible, but the data interpretation has been made as transparent as possible. Generalisation of the findings is not possible, but some issues raised may have resonance in other jurisdictions, particularly where professional roles and legislation resembles Dutch law. In common with other studies, few professionals openly objecting to assisted dying were recruited. Seeking ways to include their perceptions in the design stages of assisted dying research should be encouraged. This study also lacks the perspectives of a psychologist and spiritual advisor.

\section{Conclusion}

Conducted to explore the pragmatic realities of assisted dying from the perspective of healthcare professionals, some of the known challenges are confirmed. However, the findings add detail and identify new areas for further investigation. Reinforced is that assisted deaths challenge professionals and are emotionally demanding. Moreover, its implementation affects a wide range of disciplines, and nonparticipating as well as participating staff. Employers need to ensure professionals are prepared for, and have the emotional resilience to care for such work. Professionals may have a significant impact on the outcome of requests with careful assessment, open and transparent decision-making and use of palliative care safeguarding patients. Instigating measures to limit the emotional impact including proactive psychological support for professionals should be considered mandatory. Strengthening palliative care provision, and adequately preparing and supporting professionals, may require significant additional financial resources. The allocation of increased resources for training, education and psychological support should be made and spent effectively before assisted dying legislation is implemented.

\section{List Of Abbreviations}

PAS Physician-assisted suicide

\section{Declarations}




\section{Ethical and Consent to Participate:}

Approval procedures as outlined in the Methods section: Approval granted by Lancaster University Research Ethics Committee [FHMREC12017] for the United Kingdom and reviewed by the Maastricht University Executive Committee [METC12-5-043] for the Netherlands. Informed written consent was obtained from all participants prior to the commencement of the interviews.

\section{Consent to Publication:}

Not applicable

\section{Availability of Data and Materials:}

Analytical material is available from the corresponding author on reasonable request providing the request is not in conflict with the study's ethical approval.

\section{Competing Interests:}

The author(s) have no potential conflicts of interest with respect to the research, authorship, and/or publication of this article.

\section{Funding:}

With the exception of partial assistance from the employer of the first author for $\mathrm{PhD}$ in Palliative Care programme fees, no financial support has been given for the research, authorship, and/or publication of this article.

\section{Authors Contributions:}

DL designed the study under the supervision of NP. DL conducted the interviews and data analysis with supervision from NP. The paper was written by DL and reviewed by NP. All authors have read and approved the final manuscript. 
Acknowledgments: The author would like to thank the Dutch healthcare professionals who participated, research supervisors Dr Nancy Preston and Dr Anne Grinyer, and fellow students Drs Gamondi and Gerson from Lancaster University, End of Life Care Observatory for their encouragement, guidance and advice.

Author's Information: DL is a Clinical Nurse Specialist and Lecturer in Palliative Care (UK) with experience in clinical practice, and Higher Education. NP is a Professor of Palliative Care supervising PhD students with an interest in palliative care including assisted dying.

\section{References}

1. Commission for Assisted Dying (2012) The Commission on Assisted Dying Final Report, Demos, London. http://www.demos.co.uk/files/476_CoAD_FinalReport_158x240_I_web_single-NEW_.pdf? 1328113363 (accessed 7 June 2019)

2. Legemaate, J. Classifications and Definitions. Dutch Developments. In Youngner S, Kimsma G, eds. Physician-Assisted Death in Perspective. Assessing the Dutch Experience. Cambridge: Cambridge University Press. 2012;21-33

3. Hudson P, Hudson R, Philip J et al. Legalizing physician-assisted suicide and/or euthanasia: Pragmatic implications. Palliat Support Care, 2015;13;1399-1409.

4. The Termination of Life on Request and Assisted Suicide (Review Procedures) Act. 2002; https://euthanasia.procon.org/sourcefiles/netherlands-termination-of-life-on-request-and-PAS-act.pdf (accessed 28 Nov 2018)

5. Griffiths J, Bood A, Weyers H, Euthanasia and Law in the Netherlands. Amsterdam: Amsterdam University Press. 1998.

6. Kimsma G, Euthanasia Consultants. Professional Assessments before Euthanasia and PhysicianAssisted Suicide in the Netherlands. In Youngner S, Kimsma G, eds. Physician-Assisted Death in Perspective. Assessing the Dutch Experience. Cambridge: Cambridge University Press. 2012;181-191

7. Regional Euthanasia Review Committees. Euthanasia Code 2018 https://english.euthanasiecommissie.nl/the-committees/documents/publications/euthanasiacode/euthanasia-code-2018/euthanasia-code-2018/euthanasia-code-2018 (accessed 7 June 2019)

8. Royal Dutch Medical Association. Euthanasia in Figures - Infographic https://www.knmg.nl/contact/about-knmg.htm (accessed 7 June 2019)

9. Royal Dutch Medical Association The Role of the Physician in the Voluntary Termination of Life. Royal Dutch Medical Association. https://www.knmg.nl/contact/about-knmg.htm (accessed 7 June 2019)

10. Lewis D, Gerson S, Gamondi C. Assisted Dying: A Global Overview. In Walshe C, Preston N, Johnston B, eds. Palliative Care Nursing. Principles and Evidence for Practice. $3^{\text {rd }}$ Maidenhead: Open University 
Press/McGraw-Hill Education 2017;391-410.

11. Dunn P, Reagan B, Tolle S et al The Oregon Death with Dignity Act: A Guidebook for Health Care Professionals. Center for Ethics in Health Care, Oregon Health and Science University.

https://www.wsha.org/wp-content/uploads/Death-with-Dignity_Death-with-dignity-guidebook.pdf (accessed 7 June 2019)

12. Griffiths J, Weyers H, Adams M. Euthanasia and Law in Europe. Portland, USA: Hart Publishing. 2008;pp.56,126.

13. NL Times. Dutch to Prosecute Doctor in Euthanasia Case. A First Since Legalizing Assisted Suicide. https://nltimes.nl/2018/11/09/dutch-prosecute-doctor-euthanasia-case-first-since-legalizingassisted-suicide (accessed $7^{\text {th }}$ June 2019)

14. End of Life Clinic [Levenseindekliniek] https://translate.google.co.uk/translate? hl=en\&sl=nl\&u=http://www.levenseindekliniek.nl/\&prev=search (accessed 9 June 2019)

15. Sheldon T, Mobile “life's end” teams start work in the Netherlands. BMJ; 2012;344:DOI doi: https://doi.org/10.1136/bmj.e1681

16. Snijdewind M, Willems D, Deliens L et al (2015) A study of the first year of the end-of-life clinic for physician-assisted dying in the Netherlands. JAMA Intern Med,175 (10): 1633-

1640.DOI:10.1001/jamainternmed.2015.3978

17. Central Committee on Research Involving Human Subjects. Your research: Is it subject to the WMO or not? https://english.ccmo.nl/investigators/legal-framework-for-medical-scientific-research/yourresearch-is-it-subject-to-the-wmo-or-not (accessed 7th June 2019)

18. Snape D, Spencer L, The Foundations of Qualitative Research. In Ritchie J, Lewis J, eds. Qualitative Research Practice. A Guide for Social Science Students and Researchers. London: Sage Publications Ltd. 2003;11-23.

19. Burr V, Social Constructionism $3^{\text {rd }}$ East Sussex: Routledge. 2003.

20. Vassy, C., Keller, R. Cross National Qualitative Health Research. In Bourgeault I, Dingwall R, de Vries R. eds. The Sage Handbook of Qualitative Methods in Health Research. London: Sage Publications Ltd. 2013;621-638

21. Beitin B, Interview and Sampling: How Many and Whom. In Gubrium J, Holstein J, Marvasti A et al, eds. The Sage Handbook of Interview Research. The Complexity of the Craft. $2^{\text {nd }}$ London: Sage Publications Ltd. 2012;243-253.

22. Robson C. Real World Research. $3^{\text {rd }}$ Chichester: John Wiley and Sons Ltd. 2011

23. Braun V, Clarke V, Using thematic analysis in psychology. Qual Res Psychol, 2006; 3(2):77-101.

24. Lewis J, Ritchie J, Generalising from Qualitative Research. In Ritchie J, Lewis J, eds. Qualitative Research Practice. A Guide for Social Science Students and Researchers. London: Sage Publications Ltd. 2003;263-284.

25. Schwandt T, Judging interpretations. New Dir Eval 2007;114,11-14.

26. Lincoln Y, Guba E, Naturalistic Inquiry. London: Sage Publications Ltd. 1985 
27. Dees $M$, Vernooij-Dassen $M$, Dekkers $W$ et a/Unbearable suffering of patients with a request for euthanasia or physician-assisted suicide: an integrative review. Psychooncology, 2010;19:339-352.

28. Willems D, Palliative Care and Physician-Assisted Death. In Youngner S, Kimsma G, eds. PhysicianAssisted Death in Perspective. Assessing the Dutch Experience. Cambridge: Cambridge University Press. 2012;202-212

29. Wasteson E, Brenne E, Higginson I et al Depression assessment and classification in palliative care patients: a systematic literature review. Palliat Med, 2009;23(8);739-753.

30. Norton E, Miller P. What their terms of living and dying might be: hospice social workers discuss Oregon's Death with Dignity Act. J Soc Work End Life Palliat Care, 2012; 8(3): 249-264.

31. Royal Dutch Medical Association/Royal Dutch Pharmacists Association (2012) Guidelines for the Practice of Euthanasia and Physician-Assisted Suicide. https://www.knmg.nl/contact/aboutknmg.htm (accessed $8^{\text {th }}$ June 2019)

32. Groenewoud J, van der Heide A, Onwuteaka-Philipsen B, et al Clinical problems with the performance of euthanasia and physician-assisted suicide in the Netherlands. N Engl J Med 2000:342:551-6.

33. Trachtenberg A, Manns B. Cost analysis of medical assistance in dying in Canada. Can Med Assoc J; 2015;189(3):E101-5. DOI:10.1503/cmaj.160650.

34. Jansen-van der Weide M, Onwuteaka-Philipsen B, van der Wal G, Granted, undecided, withdrawn, and refused requests for euthanasia and physician-assisted suicide. Arch Intern Med,2008;165:16981704

35. Materstvedt L, Palliative care ethics: The problems of combining palliation and assisted dying. Prog Palliat Care; 2013;21(3):158-164

36. World Health Organisation World Health Organisation Definition of Palliative Care. World Health Organisation. http://www.who.int/cancer/palliative/definition/en/ (accessed 9 June 2019)

37. Onwuteaka-Philipsen B, Rurup M, Pasman $R$, et a/ The last phase of life. Who requests and who receives euthanasia or physician-assisted suicide? Med Care; 2010;48(7):596-603.

38. van Marwijk H, Haverkate I, van Royen P, et al (2007) Impact of euthanasia on primary care physicians in the Netherlands. Palliat Me;2007;21:609-614.

39. Parliament of Canada Statutes of Canada. Chapter 3. Parliament of Canada. http://www.parl.gc.ca/HousePublications/Publication.aspx?Language=E\&Mode=1\&Docld=8384014 (accessed 9 June 2019)

40. Sulmasy D, Ethics and the Psychiatric Dimensions of Physician-Assisted Suicide. In Jones D, Gastmans C, MacKellar C, (Eds.) Euthanasia and Assisted Suicide. Lessons from Belgium. Cambridge: Cambridge University Press. 2017;pp.49-64.

41. End of Life Clinic (2015) Annual Report. Retrieved from https://www.levenseindekliniek.nl/jaarverslag-2015 [in Dutch] (accessed 15 June 2019)

42. Harman S, Magnus D. Early experience with the California End of Life Care Option Act. Balancing institutional participation and physician conscientious objection. JAMA;2017;177(7):907-908 
43. Wenzel J, Shaha M, Klimmek R, et al. Working through grief and loss: oncology nurses' perspectives on professional bereavement. Oncol Nurs Forum;2011;38(4): E272-E802.

44. Tranter S, Josland E, Turner K, (2016) Nurses' bereavement needs and attitudes towards patient death: A qualitative descriptive study of nurses in a dialysis unit. $J$ Ren Care, 2016;101-106.

45. Boemer K, Burack O, Jopp D, Mock S, (2015) Grief after patient death: direct care staff in nursing homes and homecare. J Pain Symptom Manage, 2015; 49 (2):214-222.

46. Dreifuerst, $\mathrm{K}$, Using debriefing for meaningful learning to foster development of clinical reasoning in simulation. J Nurs Educ 2012;51(6):327-332.

47. Heise B, Giplin L, Nursing students' clinical experience with death: a pilot study. Nurs Educ Perspect, 2016;37(2):105-107.

\section{Tables}

Table 1: Jurisdictions, Permitted Practices and Legislative Date

\begin{tabular}{|l|l|l|}
\hline Jurisdiction, Permitted Practices and Legislative & Date \\
\hline United States: & Physician-assisted suicide (PAS) & Oregon (1997) \\
\cline { 3 - 3 } & & Washington State (2008) \\
\cline { 3 - 3 } & & Vermont (2013) \\
\cline { 3 - 3 } & & California (2015) \\
\cline { 3 - 3 } & & Colorado (2016) \\
\cline { 3 - 3 } & & Washington D.C (2017) \\
\cline { 3 - 3 } & & Hawaii (2018) \\
\cline { 3 - 3 } & & New Jersey (2019) \\
\cline { 3 - 3 } & & Maine (2019) \\
\hline \multirow{2}{*}{ Low Countries } & \multicolumn{1}{|c|}{ PAS and Euthanasia } & Setherlands (2002) \\
\cline { 3 - 3 } & Euthanasia & Luxembourg (2009) \\
\cline { 3 - 3 } & & 2015 \\
\hline Columbia & Euthanasia & State of Victoria 2018 \\
\hline Canada & PAS and Euthanasia & \\
\hline Australia & PAS and Euthanasia & \\
\hline
\end{tabular}

\section{Table 2: Participant Biographies}




\begin{tabular}{|c|l|}
\hline Professional Group & Clinical Area: Number of Assisted Dying Cases \\
\hline 1. $\quad$ Therapist & Hospice activities organiser: involved in several cases \\
\hline 2. $\quad$ Physician & Hospice: None as a conscientious objector \\
\hline 3. $\quad$ Nurse & Hospice: eight or nine cases \\
\hline 4. $\quad$ Nurse Manager & Hospice: five or six cases \\
\hline 5. $\quad$ Psychiatric Nurse & Hospice: four cases \\
\hline 6. $\quad$ Nurse & Respiratory ward: one case \\
\hline 7. $\quad$ Nurse & Ward nurse: two case \\
\hline 8. $\quad$ Physician & On a training rotation: one death and a refused request \\
\hline 9. Nurse & Rehabilitation: one case \\
\hline 10. Therapist & Creative therapist: therapeutic work with one patient \\
\hline 11. Physician & Elderly care doctor: three cases \\
\hline 12. Volunteer/nurse & Retired nurse working at time of death to support staff: many cases \\
\hline 13. Physician & Respiratory ward: two deaths and five requests \\
\hline 14. Nurse & Rehabilitation ward : one cases \\
\hline 15. Therapist & Physiotherapist: received expressions of interest and assessed seriousness \\
\hline 16. Physician & Internal Medicine: not specified \\
\hline 17. Nurse & Ward nurse: one death, but many requests \\
\hline 18. Physician & Respiratory ward: one cases \\
\hline 19 Therapist & Speech and language: two cases \\
\hline 20. Nurse & Ward : two deaths and many requests \\
\hline 21. Physician & Elderly care/family physician: four deaths and approx. 40 requests \\
\hline
\end{tabular}

Table 3: Questioning Guide 


\section{Questioning Guide}

- What sort of cases have they been involved in? Euthanasia and/or physician-assisted deaths? Or do they abstain from cases?

- Experience: How were they involved? How many patients? What type of patients? E.g. what conditions and in what age groups? How long was their relationship with the patient?

- Where there any particularly difficult areas to address?

- How do they feel after the patient had died? Any emotional challenges? If yes, what were these? What, if any, supportive networks are in place? Self-support mechanisms? Was any extra support needed?

- Has the participant's attitude to assisted dying altered over time? Is the current legislative framework in the Netherlands satisfactory/adequate?

\section{Alternative Questions: Conscientious Objectors:}

- On what grounds and why? Have their views changed over time?

. How is this handled by the individual? What practical issues does it raise?

- Is it difficult to withdraw from the care of such patients? Is it impactful or not?

- Would staff member still be involved in the care of the family?

. Do they have any thoughts about the current legislative framework in the Netherlands?

Table 4: Main and Subthemes 


\begin{tabular}{|c|c|}
\hline Theme & Subthemes \\
\hline Assessment and Its Challenges & $\begin{array}{l}\text { Frequency of Requests } \\
\text { Exploration and Negotiation } \\
\text { Perceptions of Patients' Personal Characteristics } \\
\text { Demanding Patients and Families } \\
\text { Support and Objection } \\
\text { First Palliative Care } \\
\text { Changing Minds and Boundaries } \\
\text { Psychological Status } \\
\text { Granting and Refusing Requests } \\
\text { Assessing and Supporting Families } \\
\text { The End of Life Clinic: Challenging Safe Assessment? }\end{array}$ \\
\hline Preparing Professionals & $\begin{array}{l}\text { Preparation: 'Averij'? } \\
\text { Use of Supportive Networks } \\
\text { 'Is everyone comfortable?' }\end{array}$ \\
\hline Assisting a Death & $\begin{array}{l}\text { Meeting Final Requests } \\
\text { Managing the Death } \\
\text { Saying Goodbyes and Life's End } \\
\text { Administering Lethal Drugs } \\
\text { It's Never Normal } \\
\text { The Use of Humour }\end{array}$ \\
\hline Bereavement Care and Beyond & $\begin{array}{l}\text { After-death Procedures } \\
\text { Waiting for the All Clear } \\
\text { Emotional Experience and Coping Strategies } \\
\text { Bereavement Protocols } \\
\text { Families and Grieving }\end{array}$ \\
\hline
\end{tabular}

\section{Supplementary Files}

This is a list of supplementary files associated with this preprint. Click to download.

- supplement1.docx 